\title{
Four pandemics: lessons learned, lessons lost
}

\author{
Joseph V. Pergolizzi ${ }^{1}$, Jo Ann LeQuang ${ }^{1}$, Robert Taylor ${ }^{1}$, Charles Wollmuth ${ }^{1}$,

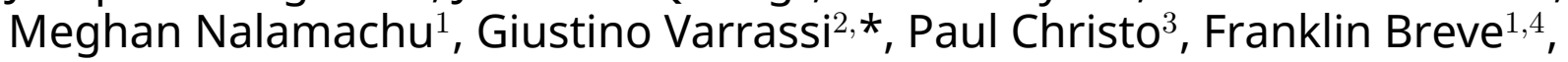 \\ Peter Magnusson ${ }^{5,6}$
}

\author{
${ }^{1}$ NEMA Research, Inc., Naples, Florida, \\ United States of America \\ ${ }^{2}$ Paolo Procacci Foundation, via Tacito 7 , \\ 00193 Rome, Italy \\ ${ }^{3}$ Associate Professor, Division of Pain \\ Medicine, Johns Hopkins University \\ School of Medicine, Baltimore, \\ Maryland, United States of America \\ ${ }^{4}$ Temple University School of Pharmacy, \\ Temple University, Philadelphia, \\ Pennsylvania, United States of America \\ ${ }^{5}$ Cardiology Research Unit, Department \\ of Medicine, Karolinska Institutet, \\ Stockholm, SE-171 76, Sweden \\ ${ }^{6}$ Centre for Research and Development, \\ Uppsala University/Region Gävleborg, \\ Gävle, SE-801 87, Sweden
}

\section{*Correspondence}

giuvarr@gmail.com

(Giustino Varrassi)

\begin{abstract}
In the past 100 years, the world has faced four distinctly different pandemics: the Spanish flu of 1918-1919, the SARS pandemic of 2003, the H1N1 or "swine flu" pandemic of 2012, and the ongoing COVID-19 pandemic. Each public health crisis exposed specific systemic shortfalls and provided public health lessons for future events. The Spanish flu revealed a nursing shortage and led to a great appreciation of nursing as a profession. SARS showed the importance of having frontline clinicians be able to work with regulators and those producing guidelines. H1N1 raised questions about the nature of a global organization such as the World Health Organization in terms of the benefits and potential disadvantages of leading the fight against a long-term global public health threat. In the era of COVID-19, it seems apparent that we are learning about both the blessing and curse of social media.
\end{abstract}

\section{Keywords}

Coronavirus; COVID-19 pandemic; Pandemics

\section{Introduction}

In the past hundred years, the world has struggled through four major coronavirus pandemics: The Spanish flu of 1918, Severe Acute Respiratory Distress Syndrome (SARS) in 2003, H1N1 or "swine flu" in 2012, and the current novel coronavirus of 2019 associated with COVID-19. In addition to morbidity and mortality, each pandemic brought to light deficiencies and shortfalls in the healthcare system and the opportunity to create better systems to manage these emerging illnesses. In this challenging time of COVID-19, it may be helpful to reflect on these earlier pandemics. See Table 1. The Centers for Disease Control and Prevention (CDC) define epidemic as an increase in the number of cases of a disease above that which is normally expected. As such a single case of a novel disease might technically be an "epidemic" [1]. Pandemic is defined by both the CDC and the World Health Organization (WHO) as an epidemic that has spread over several countries or continents and affects a large number of people $[1,2]$.

\subsection{The Spanish flu, 1918-1919}

The Spanish flu, considered the worst pandemic in history, affected a third of all people on earth at its apex [3]. About 50 million deaths have been attributed to the Spanish flu, amounting to about $2.5 \%$ of the world population at that time [4]. So devastating was the Spanish flu that life expectancy in England and Wales decreased from 54 years (prior to the outbreak) to 41 years in 1920 [5]. The Spanish flu occurred in two successive and massive waves, creating a $\mathrm{W}$-shaped morbidity and mortality distribution curve. Deaths were often caused by a secondary bacterial bronchopneumonia, for which there was no effective antimicrobial treatment at the time. Coinciding with World War I, the Spanish flu was spread in part when large numbers of infected troops were deployed to distant lands or housed in close quarters on military posts [3]. Public health interventions such as closing schools, prohibiting large assemblies, quarantines, and what is now called "social distancing" or better "physical distancing" were practiced, even as the relatively new science of vaccines sought a biomedical response [6]. One of the key lessons learned in the Spanish flu emerged in the dire shortage of trained nurses needed to help manage the large numbers of sick and convalescent patients $[7]$.

In the United States, the Civil War exposed the urgent need for trained nurses, as nursing duties up to that time and even during the Civil War largely fell to untrained volunteers. Valiant citizens often served as nurses in battlefield conditions but lacked medical training and equipment; as volunteers they could enter and exit service as they wanted. Around 1900, official nursing schools based in hospitals had emerged, where young women could be trained as nurses in two or three years; this led to the recognition of nursing as a profession. While African-American women were among these educated nurses, many of them were denied membership in the American Nurses Association on account of race. With the outbreak of World War I, African-Americans served in the U.S. military 
TA B L E 1. A short summary of four pandemics in the past 100 years including the ongoing COVID-19 pandemic. Although SARS was associated with a relatively low number of deaths, it is considered a pandemic.

\begin{tabular}{|c|c|c|c|c|}
\hline Epidemic & Year(s) & Deaths & Lessons Learned & Still to be Learned \\
\hline Spanish flu & 1918-1919 & 50 million & Nursing shortage & $\begin{array}{l}\text { Pandemics are still possible and the world should } \\
\text { be equipped to manage them }\end{array}$ \\
\hline SARS & 2003 & 800 & $\begin{array}{l}\text { Let frontline clinicians } \\
\text { contribute to guidance }\end{array}$ & $\begin{array}{l}\text { Offer more and better ways for clinicians and } \\
\text { those with direct experience with the virus to } \\
\text { contribute to guidance }\end{array}$ \\
\hline $\mathrm{H} 1 \mathrm{~N} 1$ & 2009-2010 & $\sim 500,000$ & $\begin{array}{l}\text { WHO may not be able to } \\
\text { manage a long-term global } \\
\text { pandemic }\end{array}$ & $\begin{array}{l}\text { Need to improve WHO's ability to cut through } \\
\text { bureaucracy to get the right help to the right areas } \\
\text { of the world as fast as possible }\end{array}$ \\
\hline COVID-19 & 2019-2020 & $\begin{array}{l}>1 \text { million as of } \\
\text { date of manuscript } \\
\text { preparation }\end{array}$ & $\begin{array}{l}\text { Social media is a blessing } \\
\text { and curse }\end{array}$ & $\begin{array}{l}\text { Need greater education of the public to help them } \\
\text { learn about general health and how to interpret } \\
\text { health-related information }\end{array}$ \\
\hline
\end{tabular}

and other capacities, but African-American nurses were not permitted to serve despite a severe nursing shortage. The Red Cross originally barred black nurses from joining, because it claimed the Army could not provide "separate but equal" quarters for these nurses in the military. This racist policy was reversed in 1917. Despite political struggles, calls for action, and several black nurses who volunteered, World War I ended before any black nurses were called to military service [4]. The Spanish flu of 1918 exposed a shortage of nurses overall: there were too few nurses for the pandemic and many of the available trained nurses were serving in the armed forces. Despite humiliations and overt racism, African-American nurses found limited opportunities to serve their country in the pandemic, and those few nurses who were able to serve performed exemplary services and are credited with opening the doors of opportunity for black medical professionals in the future. In World War I, 18 black nurses served in the U.S. military; by World War II, there were over 600 black nurses in the military [4].

Following the Spanish flu pandemic, educational pathways in the United States were set up to allow people to become licensed as a practical nurse and the clinical role of nurses was better defined [8]. Men have started to enter the ranks of nurses as nursing gained professional respect and status. In 2019, the United States has 3.2 million nurses, of whom $12 \%$ are men, more than at any other time in history [9].

\subsection{Severe acute respiratory syndrome (SARS)}

The SARS virus was caused by a novel zoonotic coronavirus that emerged in 2003 as a so-called "super-spreading event", although the brunt of the pandemic was borne by Asia. Characterized by severe pulmonary damage, patients often required potentially life-saving extracorporeal membrane oxygenation (ECMO). Globally, it accounted for the fewest deaths of any of the four pandemics considered here, but it has been recognized as a pandemic in the literature [10]. SARS raised important issues about the potential of such a virus to persist with waning immunity and whether or not such a virus could be made extinct. A major question in SARS emerged in terms of how a rapidly spreading potentially life-threatening virus could overwhelm local healthcare resources and what damage this might potentially cause in under-developed nations [11]. While the SARS pandemic was limited in scope, mortality was estimated at $14 \%$ overall and exceeded $50 \%$ among patients $\geq$ 64 years [12].

One lesson learned in SARS was the life-saving role of ECMO for patients with severe respiratory illness. A second lesson was that during the brunt of the crisis, a gap appeared separating frontline clinicians from official policymakers. Infection-control experts and other authorities who had no experience in the actual care of patients with SARS became the main source of information and guidance [13]. It is thought that the serious risks associated with SARS fueled an urgent demand for SARS information (typically scarce in a crisis) which led to what is now called "social modeling." In the absence of authoritative guidelines, government mandates, or scientific protocols, people did what they observed their neighbors were doing and, likewise, clinicians copied the behaviors they observed among their peers [14]. The virus affected Asia more than other parts of the world, and this self-imposed, self-isolation behavior reportedly continued in Taiwan for months after the pandemic had abated [14]. Epidemiological findings about SARS were published only after the epidemic had ended, highlighting an information gap experienced acutely by clinicians managing the pandemic [15]. Social media was scarcely a presence in 2003 when SARS occurred; Google was founded in 1999, Facebook did not appear until 2007, and the first iPhone did not come to market until the summer of 2007.

\subsection{The H1N1 virus}

The H1N1 or "swine flu" pandemic occurred in 2009-2010 and resulted in an estimated 60 million infections worldwide with 12,000 deaths in the United States and possibly half a million deaths globally [16]. In 2007, the International Health Regulations (IHR) had gone into effect, which was an official attempt to codify lessons learned from SARS in terms of connecting front-line clinicians with politicians, regulators, and other public health authorities. The IHR was helpful in many ways: it encouraged the rapid isolation and identification of the pathogen, the swift development of diagnostic tools, and 
the immediate creation of an effective network of public health officials and other experts [17]. Shortfalls were noted when member states of the IHR lacked the ability, capacity, or resolve to meet their IHR obligations; only $58 \%$ of member states had developed their own country-specific plans for managing the H1N1 crisis as it was recommended [17]. However, the biggest deficiency of the IHR which has yet to be remedied is how the world can deal with countries who fail to take the necessary steps to protect against disease transmission, for instance, by not restricting travel or by not sharing pandemicrelated information [17]. There is no provision in the IHR for any sort of enforceable sanctions.

The H1N1 pandemic also highlighted limitations with the capabilities and authority of the WHO. Then as now, WHO is the only organization in the world with globally recognized authority to respond to a pandemic, but that responsibility brings with it inherent problems. For example, WHO must provide leadership to diverse member nations that may have distinct political, social, economic, and religious considerations. The overwhelming financial depth needed to manage a long-term pandemic may exceed what any single organization can do, which, in turn, may delay response, limit aid, and impair flexibility. While WHO has demonstrated great ability and dexterity in managing short-term health crises, the long-term management of a severe pandemic may exceed the competence and financial strength of any global organization [17]. Many nations, such as the United States, tend to favor a national response to an epidemic, but with international cooperation. It is not clear if this is a workable global strategy, particularly since there are nations who prefer that global organization manage such situations.

H1N1 also exposed the fact that data collection poses a problem for many underdeveloped nations which were overwhelmed with the medical problems of the epidemic and could not always submit accurate epidemiological data in a timely fashion [17]. This begs the question that some nations might not only fail to submit timely data reports, but may report erroneous data either because of poor practices or for more nefarious reasons, such as to downplay the extent of the pandemic [17].

During the H1N1 crisis, WHO sent 78 million doses of H1N1 vaccine to a total of 77 countries, but many countries only received the vaccine after it was no longer needed [17]. An analysis of this problem revealed it was caused by a multiplicity of factors: too little global productional capacity, technical glitches, and failures in distribution systems. While wealthier nations had offered to donate vaccines to less-developed nations, there were delays caused by extended negotiations over regulatory restrictions, importation requirements, legal liabilities, and the ability of the destination country to administer the vaccines promptly [17]. Recognition of bureaucratic obstacles and the ability to remove them swiftly is crucial for rapid response.

\subsection{COVID-19}

The novel coronavirus outbreak of 2019-2020 resulting in the potentially life-threatening disease of COVID-19 is going on at the time of writing this article [18]. This fourth pandemic of the past 100 years, among other issues [19-24] has exposed a pretty new problem for public health: misleading or false information. COVID-19 and the Spanish flu share some similar features: both diseases are highly contagious and both outbreaks occurred in an era when people left home: the Spanish flu during a world war and COVID-19 in an era of globalization. But unlike the Spanish flu, COVID-19 occurred in the era of social media and instant communications. While other pandemics relied on government or official guidance to manage the crisis and disseminate information in newspapers and later on television, COVID-19 occurred in the posttelevision era where most people obtain news from online platforms. Instantaneous reports from individuals with no clinical or scientific expertise could rapidly "go viral" along with the virus. These unfiltered accounts were sometimes helpful but often misleading. Social media in some cases shared deliberate lies, but in other cases the information was merely misleadinginterim reports, partial data, anecdotal observations, and exaggerations. Individuals without specific medical, scientific, or public health expertise found it so challenging to navigate this avalanche of information, WHO labeled it an "infodemic" that paralleled the pandemic [25].

On the one hand, social media allowed rapid dissemination of basic strategies to prevent COVID-19: hand hygiene, social or physical distancing, self-isolation. People quickly learned the key symptoms of COVID-19 and could keep up to date on the availability of test kits and learn about the steps in vaccine development. Government agencies and public health authorities took advantage of social media to share good advice and offer directives.

However, misinformation also emerged. Social media announced that drinking alcohol was a good prophylactic strategy although the opposite is the case, as alcohol may weaken the immune system and promotes dehydration [26]. Panic buying in supermarkets may have been fueled by fake news that suggested food or other essentials would soon be in short supply. There would be many other examples, but perhaps the most egregious eventually "fake news" carried and promoted by social media about COVID-19 was the notion that the virus was produced in a lab and unleashed in a sinister plot on an unsuspecting world.

Even apart from the pandemic, social media have also been a mixture of fake news, real news, truth, opinion, and speculation, and sometimes the public is unable to sort it out. Compounding the problem was the fact that official information about disease and associated mortality sometimes conflicted. Sometimes the same authorities stated, then revised information. This is not "fake news" but rather the efforts of officials and scientists on a daily basis to wrangle data. Public health and government authorities who once worked in relative obscurity now find themselves quoted or cited in near real time. A good example occurred when the French Minister of Health, Olivier Véran, stated that nonsteroidal antiinflammatory drugs, especially ibuprofen, should be avoided in COVID-19 patients. This advice, which was not based on any scientific evidence [27], was quickly retracted, but this one remark was sufficient to confuse clinicians, patients, and ordinary citizens not just in France but around the world [28]. There is no evidence that ibuprofen exacerbates COVID-19 
and there is no immediately evident mechanism by which it could do so [29, 30]. On March 18, 2020, the European Medicines Agency stated there was no scientific evidence that ibuprofen exacerbated COVID symptoms [31]. The following day, the Food and Drug Administration in the United States has stated it likewise was not aware of any scientific evidence connecting any NSAIDs, including ibuprofen, with worsening of COVID-19 symptoms [32]. WHO announced on social media that it did "not recommend against:" the use of ibuprofen in patients with COVID-19 [33]. An important lesson to be learned here is that social media amplifies all news and opinions, particularly those issued by people in authority. In this case, the ibuprofen advisory was not truly "fake news" as much as it was speculative. However, speculations that once rarely left a closed-door conference room of learned experts are now being broadcast to the general public, who is often not trained in how to interpret them. Thus, what is sometimes considered "fake news" is in reality "interim news" or "evolving news" or "opinion" based on rapid analysis of partial data by a person or small group from one particular site. Greater education of the public is needed so that they can better understand what these data mean and why data change over time.

On the other hand, social media has been beneficial during COVID-19 in that it has allowed families, friends, and business colleagues to stay in rapid, immediate, and even nearly constant touch with each other while still maintaining the required social or physical distance to thwart the spread of the disease.

\section{Conclusions}

Each of the four pandemics in the past 100 years has had a devastating effect but has also left us with lessons to learn that may blunt or even prevent future disasters. The Spanish flu exposed a shortage of trained nurses that has since been largely remedied. The SARS epidemic drove home the fact that ECMO was an important part of treatment and guidance is often urgently needed not just from experts but from frontline clinicians. In the H1N1 pandemic, the role of WHO in pandemic care was highlighted and certain key questions emerged about how well one global organization can manage a long-term pandemic. Today, in COVID-19 pandemic the role of "viral" media in the context of a viral pandemic will no doubt fuel many later studies.

\section{ETHICS APPROVAL AND CONSENT TO PARTICIPATE}

This article is based on previously conducted studies and does not contain any studies with human participants or animal performed by the authors without a previous Ethics Committee approval.

\section{AUTHOR CONTRIBUTIONS}

All the authors have equally participated to the preparation of the manuscript. All of them meet the International Committee of Medical Journal Editors (ICMJE) criteria for authorship for this article, take responsibility for the integrity of the work as a whole, and have given their approval for this version to be published.

\section{ACKNOWLEDGEMENTS}

The authors are grateful to the LeQ Medical for drafting the paper, and to the NEMA Research and the Paolo Procacci Foundation for their support in editing the manuscript.

\section{CONFLICT OF INTEREST}

The authors declare no conflict of interest.

\section{REFERENCES}

[1] Centers for Disease Control and Prevention. Section 11: Epidemic disease occurrence. Centers for disease control and prevention. Lesson 1: Introduction to epidemiology. 2012. Available at: https://www.cdc.gov/ csels/dsepd/ss1978/lesson1/section11.html (Accessed: 31 October 31, 2020).

[2] Kelly H. The classical definition of a pandemic is not elusive. World Health Organization. Bulletin of the World Health Organization. 2011. Available at: http: //www9. who. int/bulletin/volumes/89/ 7/11-088815/en/ (Accessed: 31 October, 2020).

[3] Lüthy IA, Ritacco V, Kantor IN. One hundred years after the "Spanish" flu. Medicina. 2018; 78: 113-118.

[4] Jones MM, Saines M. The Eighteen of 1918-1919: black nurses and the great flu pandemic in the United States. American Journal of Public Health. 2019; 109: 877-884.

[5] Roser M. The Spanish flu (1918-1920): the global impact of the largest influenza pandemic in history. Our World in Data. 2020. Available at: https://ourworldindata.org/spanish-flu-largestinfluenza-pandemic-in-history (Accessed: 31 October, 2020).

[6] Schwartz JL. The Spanish flu, epidemics, and the turn to biomedical responses. American Journal of Public Health. 2018; 108: 1455-1458.

[7] Henry S. Nurses in the face of the Great War's epidemics. Soins. 2014; 24-27.

[8] Bauers S. 5 questions: how the 1918 Spanish flu pandemic changed the nursing profession. In: Tribune Content Agency LLC. 2018.

[9] U.S. Bureau of labor statistics. Labor force statistics from the current population survey. U.S. Bureau of Labor Statistics. 2020. Available at: https://www.bls.gov/cps/cpsaat11.htm (Accessed: 31 October, 2020).

[10] Yang Y, Peng F, Wang R, Guan K, Jiang T, Xu G, et al. The deadly coronaviruses: the 2003 SARS pandemic and the 2020 novel coronavirus epidemic in China. Journal of Autoimmunity. 2020; 109: 102434.

[11] Dye C, Gay N. Epidemiology. Modeling the SARS epidemic. Science. 2003, 300: 1884-1885.

[12] Roos R. Estimates of SARS death rates revised upward. University of Minnesota. 2003. Available at: https://www.bls.gov/cps/ cpsaat11.htm (Accessed: 31 October, 2020).

[13] Nanji CK, Orser AB. Managing Ebola: lessons learned from the SARS epidemic. Anesthesia \& Analgesia. 2015; 121: 834-835.

[14] Bennett D, Daniel B, Chiang CF, Malani A. Learning during a crisis: the SARS epidemic in Taiwan. The Journal of Development Economics. 2015; 112: 1-18.

[15] Xing W, Hejblum G, Leung GM, Valleron AJ, Sim I. Anatomy of the epidemiological literature on the 2003 SARS outbreaks in Hong Kong and Toronto: a time-stratified review (Bibliographic Anatomy of SARS Epidemic). PLoS Medicine. 2010; 7: e1000272.

[16] Dee DL, Bensyl DM, Gindler J, Truman BI, Allen BG, D'mello T, et $a l$. Racial and ethnic disparities in hospitalizations and deaths associated with 2009 pandemic influenza A (H1N1) virus infections in the United States. Annals of Epidemiology. 2011; 21: 623-630.

[17] Fineberg H. Pandemic preparedness and response-lessons from the H1N1 
influenza of 2009. New England Journal of Medicine. 2014; 370: 13351342.

[18] Pergolizzi JV, Jr., Magnusson P, LeQuang JA, Breve F, Paladini A, Rekatsina M, et al. The Current Clinically Relevant Findings on COVID19 Pandemic. Anesthesia and Pain Medicine. 2020; 10: e103819.

[19] Pergolizzi JV Jr., Raffa RB, Varrassi G, Magnusson P, LeQuang JA, Paladini A, et al. Potential neurological manifestations of COVID-19: a narrative review. Postgraduate Medicine. 2020. [In press]

[20] Moka E, Paladini A, Rekatsina M, Urits I, Viswanath O, Kaye $\mathrm{AD}$, et al. Best practice in cardiac anesthesia during the COVID19 pandemic: practical recommendations. Best Practice \& Research: Clinical Anaesthesiology. 2020; 34: 569-582.

[21] Perchiazzi G, Pellegrini M, Chiodaroli E, Urits I, Kaye AD, Viswanath $\mathrm{O}$, et al. The use of positive end expiratory pressure in patients affected by COVID-19: Time to reconsider the relation between morphology and physiology. Best Practice \& Research: Clinical Anaesthesiology. 2020; 34: 561-567.

[22] Raudenská J, Steinerová V, Javůrková A, Urits I, Kaye AD, Viswanath $\mathrm{O}$, et al. Occupational burnout syndrome and post-traumatic stress among healthcare professionals during the novel coronavirus disease 2019 (COVID-19) pandemic. Best Practice \& Research: Clinical Anaesthesiology. 2020; 34: 553-560.

[23] Rekatsina M, Paladini A, Moka E, Yeam CT, Urits I, Viswanath O, et al. Healthcare at the time of COVID-19: a review of the current situation with emphasis on anesthesia providers. Best Practice \& Research: Clinical Anaesthesiology. 2020; 34: 539-551.

[24] Puntillo F, Giglio M, Brienza N, Viswanath O, Urits I, Kaye AD, et al. Impact of COVID-19 pandemic on chronic pain management: looking for the best way to deliver care. Best Practice \& Research: Clinical Anaesthesiology. 2020; 34: 529-537.

[25] World Health Organization. Novel Coronavirus (2019-nCoV) Situation Report-13. World Health Organization. 2020. Available at: https://www. who.int/docs/default-source/coronaviruse/ situation-reports/20200202-sitrep-13-ncov-v3.pdf (Accessed: 31 October, 2020).

[26] Marr B. Coronavirus fake news: how Facebook, Twitter, and Instagram are tackling the problem. Forbes. 2020. Available at: https: //www. forbes. com/sites/bernardmarr/2020/03/27/finding- the-truth-about-covid-19-how-facebook-twitterand-instagram-are-tackling-fake-news/\#5304f4511977 (Accessed: 31 October, 2020).

[27] Pergolizzi JV, Jr., Varrassi G, Magnusson P, LeQuang JA, Paladini A, Taylor R, et al. COVID-19 and NSAIDS: a narrative review of knowns and unknowns. Pain and Therapy. 2020; 9: 353-358.

[28] Day M. COVID-19: ibuprofen should not be used for managing symptoms, say doctors and scientists. British Medical Journal. 2020; 368: m1086.

[29] Varrassi G. Warning against the use of anti-inflammatory medicines to cure COVID-19: building castles in the air. Advances in Therapy. 2020; 37: 1705-1707.

[30] Pergolizzi JV Jr., Varrassi G, Magnusson P, LeQuang JA, Leopoulou M, Paladini A, et al. The concern about ACE/ARB and COVID-19: time to hold your horses! Journal of the American Pharmacists Association. 2020; 60: e88-e90.

[31] European Medicines Agency. EMA gives advice on the use of non-steroidal anti-inflammatories for COVID-19. European Medicines Agency. 2020. Available at: https://www.ema.europa.eu/en/ about-us/contacts-european-medicines-agency (Accessed: 31 October, 2020).

[32] Food and Drug Administration. FDA advises patients on use of non-steroidal anti-inflammatory drugs (NSAIDs) for COVID19. Food and Drug Administration. 2020. Available at: https: //www.fda.gov/drugs/drug-safety-and-availability/fdaadvises-patients-use-non-steroidal-anti-inflammatorydrugs-nsaids-covid-19 (Accessed: 31 October, 2020).

[33] World Health Organization. Could \#ibuprofen worsen disease for people with \#COVID19? Twitter. 2020. Available at: https : / twitter.com/ WHO/status/1240409217997189128 (Accessed: 31 October, 2020).

How to cite this article: Joseph V. Pergolizzi, Jo Ann LeQuang, Robert Taylor, Charles Wollmuth, Meghan Nalamachu, Giustino Varrassi, et al. Four pandemics: lessons learned, lessons lost. Signa Vitae. 2021;17(1):1-5. doi:10.22514/sv.2020.16.0096. 